\title{
MANIFESTAÇÕES PATOLÓGICAS EM FACHADAS FRONTAIS: ESTUDO DE CASO EM EDIFÍCIOS NA CIDADE DE CARAÚBAS/RN
}

\author{
ALVES, FABRÍCIO LEITE \\ Estudante \\ Universidade Federal Rural do Semi-Árido \\ Rio Grande do Norte; Brasil \\ fabricioalves80@hotmail.com
}

\author{
JÚNIOR, DORGIVAL A. SILVA \\ Professor \\ Universidade Federal Rural do Semi-Árido \\ Rio Grande do Norte; Brasil \\ dorgival.silva@ufersa.edu.br
}

\section{RESUMO}

A construção de edificações cresceu nos últimos anos e, devido à falta de planejamento, manutenções periódicas e utilização de materiais de baixa qualidade surgiu a ocorrência de manifestações patológicas nas edificações. É evidente que medidas preventivas devem ser levadas em consideração na elaboração de projeto e na fase de execução de modo a minimizar a presença dessas patologias, garantindo assim, a diminuição em despesas com manutenções preventivas. Esse trabalho objetiva analisar as manifestações patológicas ocorrentes nas fachadas frontais em três edificações na cidade de Caraúbas/RN, prever as possíveis causas e contribuir com eventuais soluções para os ocorridos. O estudo expõe uma pesquisa literária das patologias que predominam na edificação, reconhecidas por meio de inspeção visual e registros fotográficos. Os resultados obtidos mostraram que as fissuras e o destacamento de revestimento cerâmico são as manifestações patológicas mais comuns dentre as edificações analisadas.

Palavras-chave: Engenharia civil, manutenção, manifestações patológicas, edificações.

\section{ABSTRACT}

Construction of buildings has grown in recent years and due to lack of planning, periodic maintenance and use of low quality materials, pathological manifestations in buildings have arisen. It is evident that preventive measures must be taken into consideration in project design and implementation phase in order to minimize the presence of these pathologies, thus ensuring a reduction in expenses with preventive maintenance. This paper aims to analyze the pathological manifestations that occur in the front facades in three buildings in the city of Caraúbas / RN, to predict the possible causes and to contribute with eventual solutions to those occurred. The study exposes a literary research of the predominant pathologies in the building, recognized through visual inspection and photographic records. The results showed that the cracks and the detachment of ceramic tiles are the most common pathological manifestations among the analyzed buildings.

Keywords: Civil engineering, maintenance, pathological manifestations, buildings.

\section{INTRODUÇÃO}

Ultimamente a construção civil alavancou no Brasil à medida que a população passou por um avanço econômico. A partir disso, segundo Sampaio (2017), muitas das edificações construídas foram executadas sem planejamentos de projetos e, ao longo dos anos, apresentaram diversos problemas em sua estrutura, denominados de manifestações patológicas na Engenharia Civil. Para Rios (2017), a ciência que estuda esse fenômeno é conhecida como Patologia das Construções e determina as causas, mecanismos de ocorrência, formas de manifestação e consequências das complicações que interferem na vida útil das edificações.

A NBR 15.575-1 (ASSOCIAÇÃO BRASILEIRA DE NORMAS TÉCNICAS, 2013) define vida útil como sendo o intervalo de tempo em que um edifício e seus sistemas exercem as atividades aos quais foram projetados e construídos levando em consideração a periodicidade e a correta execução dos processos de manutenção. A vida útil das fachadas das edificações está relacionada a diversos fatores, segundo Bauer, Castro e Silva (2015). Sendo eles: a vida útil prevista em projeto, as características dos materiais, ao cumprimento das especificações de projeto executivo durante toda a construção, ao adequado uso e operação da edificação, à constância e efetividade das operações de limpeza e manutenção, bem como de alterações climáticas, níveis de poluição no local da edificação e mudanças no entorno da mesma ao longo do tempo.

É imprescindível a identificação das manifestações patológicas, visto que, quando é aplicada em edificações que apresentam alguma ocorrência deste fenômeno, é elemento relevante para avaliação do grau de deterioração e estudo dos mecanismos intervenientes. Diante disso, tanto a terminologia empregada nessa identificação, quanto o reconhecimento errôneo das tipologias das manifestações, concedem erros significativos no diagnóstico dos problemas 
dos revestimentos. Uma das grandes preocupações com o aparecimento das manifestações patológicas é a de que, boa parte dos danos possui caráter evolutivo, podendo levar a estrutura a uma situação de perigo num curto prazo (CÁNOVAS, 1988).

Segundo a NBR 13755 (ASSOCIAÇÃO BRASILEIRA DE NORMAS TÉCNICAS, 2017), revestimento externo é o conjunto de camadas superpostas e intimamente ligadas, constituído pela estrutura suporte, alvenarias, camadas sucessivas de argamassas e revestimento final.

Os revestimentos de fachadas desempenham diversas funções em uma edificação (LIMA, 2018). As principais funções são: proteção da estrutura e dos elementos de vedação, melhora o desempenho térmico e acústico e melhora a estética da edificação. Contudo, as edificações estão sujeitas às patologias construtivas, as quais possuem caráter evolutivo, podendo levar a estrutura a uma situação de perigo em curto prazo.

O estudo sistemático dos problemas patológicos a partir de suas manifestações características permite um conhecimento mais aprofundado das causas, segundo Ioshumoto (1988). Além disso, contribui para um melhor entendimento das etapas dos processos de produção e subsidia os trabalhos de recuperação e manutenção das edificações, facilitando assim, para a adoção de medidas de prevenção.

Para tanto, o objetivo deste trabalho é identificar a ocorrência de manifestações patológicas nas fachadas frontais em três edificações na cidade de Caraúbas/RN, prever as possíveis causas e indicar eventuais soluções.

\section{METODOLOGIA}

O presente trabalho trata-se de um estudo qualitativo, fundamentado em conceitos teóricos e científicos empregados na elaboração da revisão bibliográfica e aplicando metodologia básica (elaborada pelos próprios autores) para investigação e análise de problemas encontrados nas fachadas frontais das edificações estudadas.

Para efetuar os levantamentos dos danos detectáveis (fissuração, eflorescência, destacamentos, etc.) foi realizada inspeção in loco efetuada por registros fotográficos por membros desse trabalho.

Para tornar o processo do estudo de caso de problemas patológicos mais simples e objetivo, desenvolveu-se um fluxograma sistemático como forma de análise de problemas. A metodologia desenvolvida é fundamentada em 5 etapas, conforme são expostas na Figura 1.

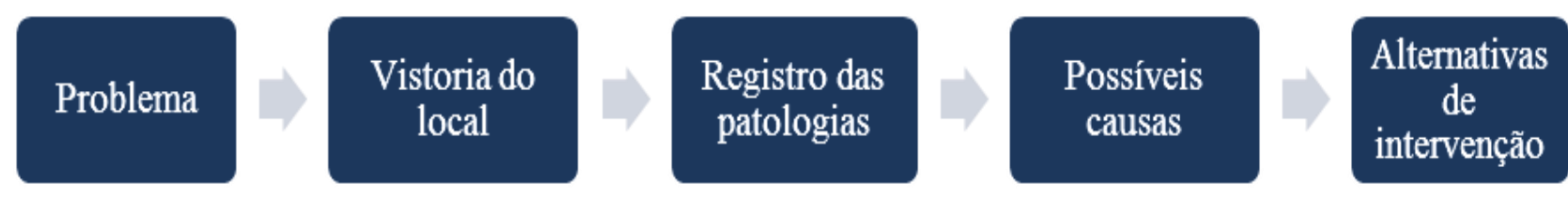

Figura 1: Metodologia de análise de patologias na edificação estudada

\subsection{Análise dos casos de estudo}

Foram consideradas 3 (três) edificações distintas e determinaram-se alguns critérios de avaliação para a escolha dessas edificações, sendo eles: situar-se na cidade de Caraúbas/RN e apresentar manifestações patológicas de forma evidente em suas fachada frontais. Além destes critérios, não foram levados em consideração o uso e ocupação das edificações, porém, teve-se enfoque na vida útil destas.

Na Tabela 1 estão dispostas as principais informações das construções escolhidas.

Tabela 1 - Uso e ocupação das edificações analisadas

\begin{tabular}{c|c}
\hline Caso & Uso e ocupação \\
\hline A & Residencial \\
\hline B & Residencial \\
\hline C & Depósito \\
\hline
\end{tabular}

A edificação representada pelo caso A é do tipo residencial, localizada em rua S/N. O caso B é representado por uma residência localizada na rua João Gomes de Oliveira. A terceira edificação, caso C, é um depósito localizado na rua $\mathrm{S} / \mathrm{N}$, no centro da cidade. 
Todas as edificações são pertencentes a cidade de Caraúbas/RN e possuem fachada frontal inferior a $10 \mathrm{~m}^{2}$. Através das informações coletadas, notou-se que as fachadas de ambas as construções foram executadas em concreto convencional, com diversos elementos de vedação (tijolos maciços e cerâmicos).

\subsection{Dados considerados para o estudo de caso}

O método utilizado neste trabalho, organiza os dados obtidos em tabela levando em consideração as manifestações patológicas encontradas. Para este trabalho não foram consideradas as quantidades de manifestações patológicas identificadas, grau de insalubridade, efeitos estéticos, dentre outras formas, mas sim, as principais manifestações patológicas de fácil visualização nas fachadas frontais dos três casos analisados.

Foi possível prever, através da inspeção visual e registro fotográfico, as possíveis causas para ocorrência das manifestações patológicas e, posteriormente, serem lançadas propostas de intervenção a fim de solucionar tais problemas.

\section{RESULTADOS E DISCUSSÃO}

As principais patologias identificadas na visita in loco de cada caso estudado estão dispostas a seguir. Também foram destacadas as características mais reconhecidas das manifestações patológicas observadas. Todas essas informações serão de fundamental importância para análise dos problemas encontrados e, posteriormente, servirão para as possíveis soluções destas.

\subsection{Caso A}

A fachada da primeira edificação estudada é construída em cimento convencional e com tijolos maciços, conforme é mostrada na Figura 2. A edificação possui mais de 10 anos de construção e sua fachada frontal não passou por reparos nos últimos anos, os quais vieram a causar algumas manifestações patológicas indesejáveis.

Pela afirmação do proprietário da residência, sua casa não possui plano de manutenção, sendo que as intervenções para algum tipo de recuperação são realizadas quando o grau de deterioração é extremamente elevado.

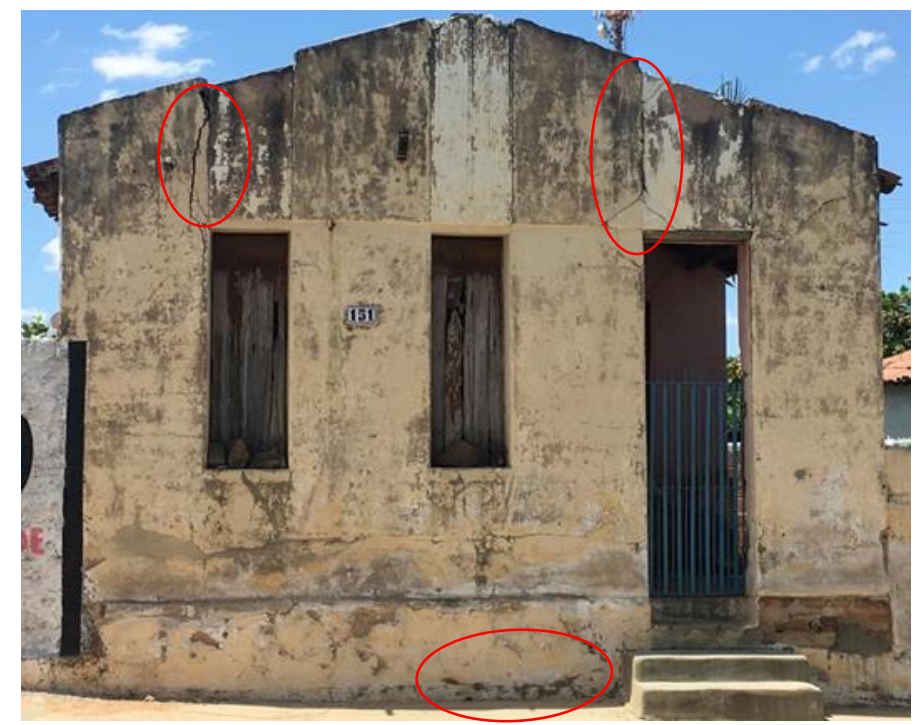

Figura 1: Manifestações patológicas identificadas na primeira edificação analisada

Na Tabela 2 estão organizadas as principais patologias observadas na edificação estudada, as quais estão destacadas na Figura 2.

Tabela 2 - Levantamento de manifestações patológicas identificadas na primeira edificação

\begin{tabular}{c|c}
\hline Número & Manifestação patológica \\
\hline 1 & Fissuras \\
\hline 2 & Trincas \\
\hline 3 & Rachaduras \\
\hline 4 & Eflorescência \\
\hline
\end{tabular}


As principais patologias identificadas foram fissuras, trincas e rachaduras. A diferença entre estas é a dimensão da abertura.

As aberturas com até $0,5 \mathrm{~mm}$ são chamadas de fissuras, as maiores de $0,5 \mathrm{~mm}$ e menores de $1,0 \mathrm{~mm}$ são chamadas de trincas e por fim as com aberturas maiores de $1,0 \mathrm{~mm}$ são denominadas rachaduras.

O aparecimento dessas patologias pode ser explicado em virtude da retração hidráulica do cimento, da retração do endurecimento do cimento, da movimentação térmica e, também, do ataque de sulfatos ao cimento do concreto utilizado para a construção da fachada da residência. No caso das rachaduras, devem ter atenção imediata, uma vez que estas possuem um estágio mais avançado.

Uma solução para o reparo desses tipos de patologias é a inserção de impermeabilizantes acrílicos aplicados em duas a três demãos. Um exemplo comum são as fibras sintéticas de polipropileno bastante utilizadas na argamassa, as quais inibem a retração hidráulica na mistura.

Outra patologia identificada na residência, mesmo em pequena quantidade, foi a presença de eflorescências, as quais se dão quando há infiltração de água e ela acaba dissolvendo os sais presentes no cimento - principalmente o hidróxido de cálcio. Para isso, deve-se ser realizada a remoção dessa área deteriorada e, em seguida, impermeabiliza-la para fazer uma nova parede (chapisco, emboço e reboco).

\subsection{Caso B}

A fachada da segunda edificação estudada, Figura 3, é construída com cimento convencional e com tijolos cerâmicos. A edificação possui 12 anos de construção e sua fachada frontal teve modificação a pouco mais de 24 meses. A partir da última manutenção realizada na fachada da casa, foi implantado revestimento cerâmico em uma pequena área por fins estéticos.

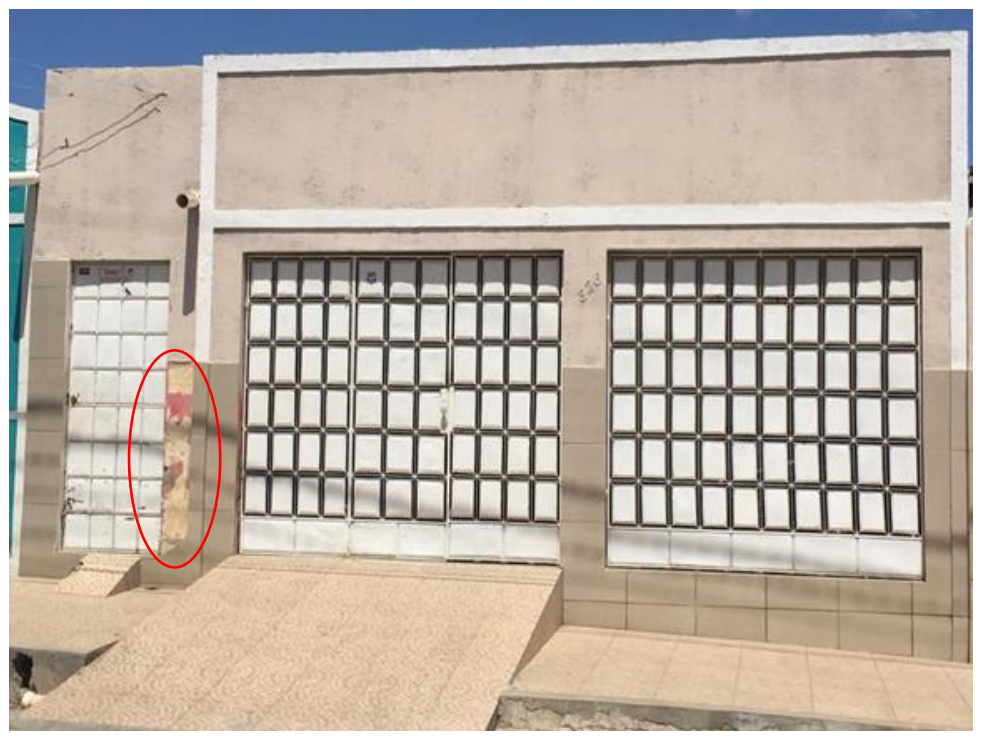

Figura 2: Manifestações patológicas identificadas na segunda edificação analisada

Apesar de ter sido feita manutenção em um curto período de tempo, comparada as outras edificações, foi identificado o destacamento do revestimento cerâmico (destacado na Figura 2) em uma parte da fachada da residência. Pela inspeção visual da fachada frontal, a causa desse acontecimento pode ser explicada devido a falhas de execução de assentamento, além do incorreto preenchimento da argamassa colante no verso da placa cerâmica.

Então, para não ocorrer esse tipo de patologia, é imprescindível ser executado um bom assentamento cerâmico na alvenaria e ser estabelecido um material colante correto a ser utilizado.

\subsection{Caso C}

A fachada da terceira edificação estudada é construída com cimento convencional e com tijolos maciços, conforme é mostrada na Figura 4. É perceptível a presença dos tijolos maciços a partir de manifestações patológicas na edificação. Não foi definido o ano do último reparo feito na fachada do depósito. Pelo que pôde ser observado, o depósito foi abandonado há vários anos. 


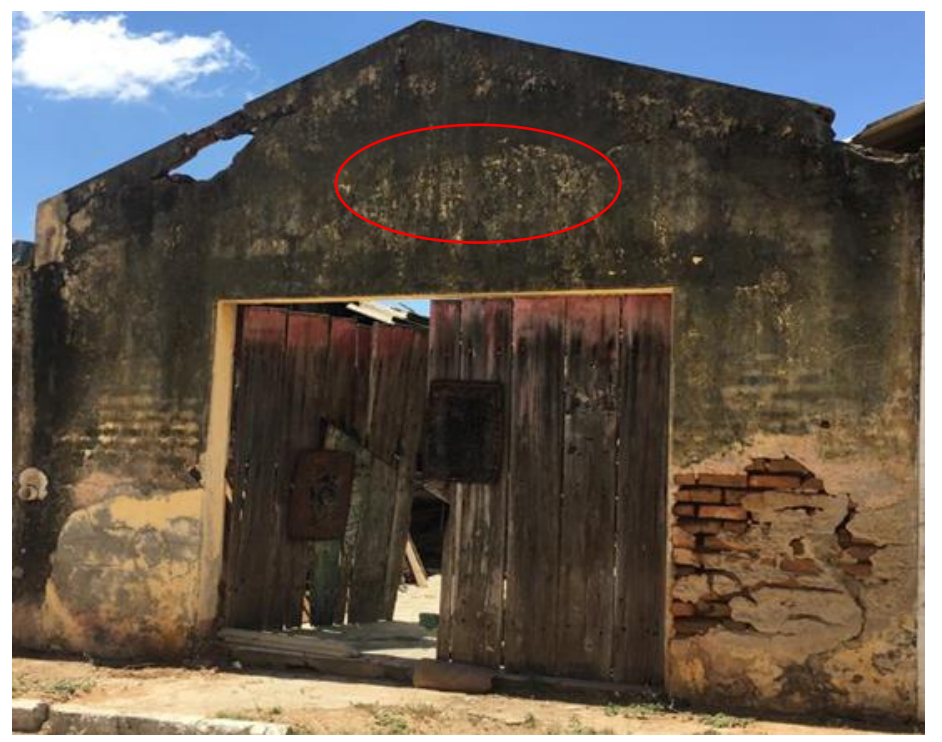

Figura 3: Manifestações patológicas identificadas na terceira edificação analisada

A patologia predominante na fachada do depósito, conforme é bem mostrada na Figura 4, são manchas de sujeiras e vegetação parasitária (mofo/bolor). As possíveis causas para manifestação dessa patologia são as propriedades dos materiais utilizados e a incidência direta da chuva e pouca exposição ao sol devido à posição da edificação.

Algumas alternativas recomendadas para reparo desse tipo de anomalia são:

- Limpeza da fachada frontal com utilização de jato pressurizado de água;

- Escovação com escova de cerdas e solução de hipoclorito de sódio;

- Aplicação de pintura impermeabilizante ou revestimento com material impermeável.

Outra anomalia encontrada na fachada frontal do depósito foi, o reboco da alvenaria caindo. Pelo que foi percebido, a alvenaria adquiriu umidade, e esta, por sua vez, fungos que vieram deteriorar a parede. Para reparo deste tipo de problema é importante fazer um novo reboco com adição de um impermeabilizante, como por exemplo, argamassa polimérica.

\section{CONSIDERAÇÕES FINAIS}

As manifestações patológicas encontradas na construção civil possuem diversas origens e, geralmente, aparecem devido à falta de planejamento e manutenções e de materiais de boa qualidade. A consequência de tudo isso são nos gastos com reparos futuros, a fim de recuperar a funcionalidade e utilização das edificações.

Foram identificadas várias manifestações patológicas nos três casos analisados, sendo eles: fissuras, trincas, rachaduras, eflorescências, reboco caindo, destacamento do revestimento cerâmico e manchas de sujeiras e vegetação parasitária. Sendo que dentre estas, os mais comuns nas edificações são fissuras e destacamento cerâmico.

É evidente que será necessário a elaboração de um projeto para prever as chances de falhas e determinar os materiais e métodos de construção, além de uma correta execução controlada para diminuir, ou até eliminar, o surgimento de manifestações patológicas e otimizando a vida útil da edificação.

Portanto, uma alternativa para diminuir o aparecimento de manifestações patológicas em fachadas de edificações é um programa eficiente de inspeção e manutenção para assegurar a durabilidade e a minimização de gastos.

\section{AGRADECIMENTOS}

Agradecemos ao apoio financeiro do projeto AAMEG e à Universidade Federal Rural do Semi-Árido para apresentar esta pesquisa.

\section{REFERÊNCIAS}


ASSOCIAÇÃO BRASILEIRA DE NORMAS TÉCNICAS. NBR 13.755: Revestimentos cerâmicos de fachadas e paredes externas com utilização de argamassa colante - Projeto, execução, inspeção e aceitação - Procedimento, Rio de Janeiro, 2017.

ASSOCIAÇÃO BRASILEIRA DE NORMAS TÉCNICAS. NBR 15.575-1: Edificações habitacionais - Desempenho: Requisitos gerais, Rio de Janeiro, 2013.

BAUER, E.; CASTRO, E. K.; SILVA, M. N. B. Estimativa da degradação de fachadas com revestimento cerâmico: estudo de caso de edifícios de Brasília. Cerâmica. v. 61, n. 358, p. 151-159, 2015.

CÁNOVAS, M. F. Patologia e Terapia do Concreto Armado. Tradução de M. C. Marcondes; C. W. F. dos Santos; B. Cannabrava. $1^{a}$ ed. São Paulo: Ed. Pini, 1988.

IOSHUMOTO, E. Incidência de manifestações patológicas em edificações habitacionais. In: Tecnologia de edificações. São Paulo: Pini: IPT, 1988. p. 545-548.

LIMA, L. L. Patologias em revestimentos de fachadas. 2018. 52f. Trabalho de Conclusão de Curso - Universidade Federal da Paraíba, João Pessoa, 2018.

RIOS, F. R. A. et. al. Manifestações Patológicas Construtivas em Edificações no Centro de Campina Grande-PB. TEMA - Revista Eletrônica de Ciências. v. 18, p. 1-17, 2017.

SAMPAIO, G. S. Análise das Patologias nas Fundações Oriundas de Recalque Diferencial Através de um Estudo de Caso. Constuindo. v. 9, n. 2, p. 16-26, 2017. 